BRAVILLIAN JOURNAL

www.bjournal.com.br
ISSN 0100-879X

Volume 42 (12) 1119-1247 December 2009

BIOMEDICAL SCIENCES

AND

CLINICAL INVESTIGATION

Braz J Med Biol Res, December 2009, Volume 42(12) 1230-1235

Treadmill exercise testing of asymptomatic men and women without evidence of heart disease

W.A. Chalela, R.B. Fukushima, F. Araujo, A.C.P. Lima, P.J. Moffa and A.J. Mansur

The Brazilian Journal of Medical and Biological Research is partially financed by
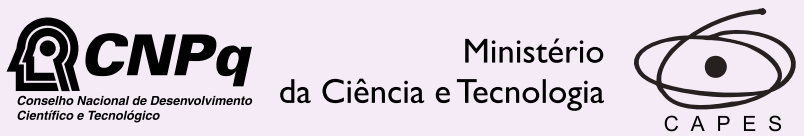

Ministério da Educação

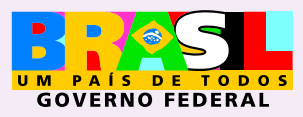

Institutional Sponsors 


\title{
Treadmill exercise testing of asymptomatic men and women without evidence of heart disease
}

\author{
W.A. Chalela, R.B. Fukushima, F. Araujo, A.C.P. Lima, P.J. Moffa and A.J. Mansur \\ Instituto do Coração, Faculdade de Medicina, Universidade de São Paulo, \\ São Paulo, SP, Brasil
}

\begin{abstract}
The aim of this study was to test the hypothesis of differences in performance including differences in ST-T wave changes between healthy men and women submitted to an exercise stress test. Two hundred (45.4\%) men and 241 (54.6\%) women (mean age: $38.7 \pm 11.0$ years) were submitted to an exercise stress test. Physiologic and electrocardiographic variables were compared by the Student $t$-test and the chi-square test. To test the hypothesis of differences in ST-segment changes, data were ranked with functional models based on weighted least squares. To evaluate the influence of gender and age on the diagnosis of ST-segment abnormality, a logistic model was adjusted; $\mathrm{P}<0.05$ was considered to be significant. Rate-pressure product, duration of exercise and estimated functional capacity were higher in men $(P<0.05)$. Sixteen $(6.7 \%)$ women and $9(4.5 \%)$ men demonstrated ST-segment upslope $\geq 0.15 \mathrm{mV}$ or downslope $\geq 0.10 \mathrm{mV}$; the difference was not statistically significant. Age increase of one year added $4 \%$ to the chance of upsloping of segment ST $\geq 0.15 \mathrm{mV}$ or downsloping of segment ST $\geq 0.1 \mathrm{mV}$ $(P=0.03$; risk ratio $=1.040,95 \%$ confidence interval $(C l)=1.002-1.080)$. Heart rate recovery was higher in women $(P<0.05)$. The chance of women showing an increase of systolic blood pressure $\leq 30 \mathrm{mmHg}$ was $85 \%$ higher $(P=0.01$; risk ratio $=1.85$, $95 \% \mathrm{Cl}=1.1-3.05)$. No significant difference in the frequency of ST-T wave changes was observed between men and women. Other differences may be related to different physical conditioning.
\end{abstract}

Key words: ST-T wave changes; Exercise stress test; Asymptomatic; Women

\section{Introduction}

Physiologic and electrocardiographic variables of men and women submitted to exercise stress test are considered to differ (1-4). The poor predictive value of ischemic ST changes during exercise in women has been emphasized $(1,4)$. For the interpretation of the tests in women it has been recommended to take into consideration a lower pre-test probability of disease in comparison to men $(2,3)$ and a lower sensitivity of ST-segment changes for the diagnosis of myocardial ischemia (4).

Differences in sensitivity, specificity and diagnostic value of ST-segment and $\mathrm{T}$ wave changes have been reported $(4,5)$. Furthermore, in the recovery after exercise, heart rate $(6-8)$ and blood pressure $(9,10)$ differences may also be present. These studies were performed in large series of patients and yielded relevant information. Nevertheless, we did not find recent studies comparing the exercise stress test of asymptomatic men and women without any evidence of heart disease after clinical examination.
We performed this study to evaluate variables of the exercise stress test in asymptomatic men and women without any evidence of heart disease after careful clinical and laboratory examination to test the hypothesis of differences in response between men and women. We were specifically interested in the comparison of ST-segment alterations between men and women.

\section{Material and Methods}

\section{Study protocol}

A cohort of asymptomatic individuals with no evidence of heart disease after careful clinical and laboratory examination was established to evaluate the exercise stress test. This cohort was established from 1998 onwards in a large General Outpatient Clinic of a tertiary care university hospital dedicated to cardiology that also provides primary and secondary levels of care. Asymptomatic individuals with

Correspondence: W.A. Chalela, Serviço de Eletrocardiologia, InCor, FM-USP, Av. Dr. Eneas C. Aguiar, 44, 05403-900

São Paulo, SP, Brasil. Fax: +55-11-3069-5328. E-mail: wchalela@incor.usp.br

Received January 3, 2009. Accepted October 13, 2009. Available online November 6, 2009. Published December 4, 2009. 
normal clinical examination, as well as normal electrocardiogram and chest $\mathrm{X}$-ray, were eligible and were invited to participate in the study. After informed written consent, participants volunteered and were submitted to further laboratory work-up including electrocardiographic exercise stress test, echocardiography, hemoglobin, hematocrit, leukocyte count, serum glucose, cholesterol, triglycerides, thyroid-stimulating hormone (TSH), and creatinine. Twodimensional transthoracic echocardiography was performed according to a standard technique following published guidelines (11).

\section{Inclusion criteria}

Asymptomatic Brazilian men and women older than 18 years with a normal clinical examination, as well as normal electrocardiogram, chest X-ray, echocardiogram, and laboratory evaluation were included in the study.

\section{Exclusion criteria}

Individuals with symptoms of cardiovascular disease, systemic hypertension, Trypanosoma cruzi infection (Chagas' disease microorganism), diabetes mellitus, TSH $<0.05$ or $>8 \mathrm{mg} / \mathrm{dL}$, chronic obstructive pulmonary disease, asthma, renal failure, chronic inflammatory diseases, osteoarticular diseases, chronic anemia, neoplasia, and an abnormal electrocardiogram or chest X-ray were excluded from the study.

\section{Study sample}

A total of 441 individuals were studied, 200 (45.4\%) men and 241 (54.6\%) women, mean age $38.7 \pm 11.0$ years (range 18-74 years; Table 1). Seventy-eight participants were smokers, 37 of them (8.9\%) men and 41 (10\%) women. The baseline characteristics of the study sample are presented in Table 2.

Treadmill electrocardiographic exercise stress test. The test was performed on the Fukuda Denshi ML-8000 Star model (Japan) according to the Ellestad exercise protocol (12). Predicted peak heart rate was calculated as 220 age. Individuals were encouraged to exercise until they experienced limiting symptoms, even if $85 \%$ of maximum

Table 1. Age distribution of the men and women of the study sample.

\begin{tabular}{lccr}
\hline Age (years) & Men & Women & \multicolumn{1}{c}{ Total } \\
\hline $18 \mid-29$ & $46(23 \%)$ & $51(21.2 \%)$ & $97(21.9 \%)$ \\
$30 \mid-39$ & $54(27 \%)$ & $74(30.7 \%)$ & $128(29.1 \%)$ \\
$40 \mid-49$ & $72(36 \%)$ & $79(32.8 \%)$ & $151(34.2 \%)$ \\
$50 \mid-59$ & $22(11 \%)$ & $31(12.8 \%)$ & $53(12.1 \%)$ \\
$\geq 60$ & $6(3 \%)$ & $6(2.5 \%)$ & $12(2.7 \%)$ \\
Total & 200 & 241 & 441 \\
\hline
\end{tabular}

Data are reported as number with percent in parentheses. predicted heart rate was achieved. During each exercise stage and recovery stage, symptoms, blood pressure, and heart rate were recorded. The criteria for interruption of the exercise were physical exhaustion or exceeded maximum heart rate predicted for the patient's age. Following peak exercise, individuals walked for a 3-min cool-down period at $1.5 \mathrm{mph}$ without inclination. The ST-segment was measured $0.08 \mathrm{~s}$ after the $\mathrm{J}$ point in 3 consecutive QRS complexes with a flat baseline and $R$ wave of equal amplitude. The amplitude of the $R$ wave was measured in II, $V_{2}$ and $V_{5}$ leads and the $Q$ wave in $V_{5}$ lead. Peak exercise capacity was estimated from treadmill time and reported as metabolic equivalents. Heart rate recovery was also measured and defined as maximum heart rate minus heart rate at 1 and 2 min after exercise with the subjects walking. To diagnose a normal treadmill electrocardiographic exercise stress test we followed previously published guidelines (13). Two physicians evaluated the electrocardiographic recordings of all tests independently in a blind fashion; disagreement was resolved by consensus.

\section{Studied variables}

The following variables were studied: a) demographic, clinical and laboratory variables: age, gender, smoking, body mass index, hemoglobin, serum glucose, total cholesterol, HDL cholesterol, LDL cholesterol, triglycerides, left ventricle myocardial mass index, and left ventricular ejection fraction on echocardiography (11); b) variables of the treadmill exercise stress test - we studied heart rate, maximal ST-segment depression, $\mathrm{R}$ wave amplitude and $\mathrm{Q}$ wave amplitude, systolic and diastolic blood pressure, rate-pressure product (heart rate x systolic blood pressure), duration of exercise, and estimated exercise capacity (metabolic equivalents).

\section{Statistical analysis}

After descriptive statistics, continuous variables relative

Table 2. Demographic, clinical and laboratory characteristics of the men and women of the study sample.

\begin{tabular}{lccccc}
\hline Variables & \multicolumn{3}{c}{ Men } & & \multicolumn{2}{l}{ Women } \\
\cline { 2 - 3 } \cline { 5 - 6 } & $\mathrm{N}$ & Mean $\pm \mathrm{SD}$ & & $\mathrm{N}$ & Mean $\pm \mathrm{SD}$ \\
\hline Age (years) & 200 & $39 \pm 0.8$ & & 241 & $38.5 \pm 0.7$ \\
Body mass index $\left(\mathrm{kg} / \mathrm{m}^{2}\right)$ & 188 & $26 \pm 0.3$ & & 228 & $26 \pm 0.3$ \\
Hemoglobin $(\mathrm{g} / \mathrm{dL})$ & 189 & $15.2 \pm 0.1$ & & 231 & $13.4 \pm 0.1^{*}$ \\
Creatinine $(\mathrm{mg} / \mathrm{dL})$ & 189 & $0.98 \pm 0.01$ & & 231 & $0.79 \pm 0.01^{*}$ \\
Glucose $(\mathrm{mg} / \mathrm{dL})$ & 189 & $93.8 \pm 1.6$ & & 231 & $89.9 \pm 0.7^{*}$ \\
Total cholesterol $(\mathrm{mg} / \mathrm{dL})$ & 190 & $193.7 \pm 2.7$ & & 231 & $187.9 \pm 2.1$ \\
LDL cholesterol $(\mathrm{mg} / \mathrm{dL})$ & 190 & $121.6 \pm 2.5$ & & 231 & $117.3 \pm 2.0$ \\
HDL cholesterol $(\mathrm{mg} / \mathrm{dL})$ & 190 & $43.3 \pm 1.3$ & & 231 & $50.9 \pm 0.9^{*}$ \\
Triglycerides $(\mathrm{mg} / \mathrm{dL})$ & 190 & $135.8 \pm 5.2$ & & 231 & $95.2 \pm 3.5^{*}$ \\
\hline
\end{tabular}

${ }^{*} \mathrm{P}<0.05$ compared to men (Student $t$-test). 
to gender were compared with the Student $t$-test and categorical variables relative to gender were compared using the chi-square test. To test the hypothesis of a sex-related difference regarding ST-segment in leads II, $V_{2}$ and $V_{5}$, data were ranked with functional models based on weighted least squares and submitted to categorical data analysis using the SAS System (14) and categorical data analysis (15). A logistic model was adjusted to evaluate the influence of gender and age on the diagnosis of ST-segment abnormality. A P value $<0.05$ was considered to be significant.

\section{Ethics}

The study was approved by the Ethics Committee of Human Research of the Hospital and all participants gave written informed consent.

\section{Results}

\section{Baseline clinical characteristics of the study sample}

Serum HDL cholesterol was higher in women. Hemoglobin, serum creatinine, triglycerides, glucose, and left ventricle mass index on echocardiography were higher in

Table 3. Echocardiogram characteristics of the men and women of the study sample.

\begin{tabular}{llllll}
\hline Variables & \multicolumn{2}{c}{ Men } & & \multicolumn{2}{l}{ Women } \\
\cline { 2 - 3 } & $\mathrm{N}$ & Mean $\pm \mathrm{SD}$ & & $\mathrm{N}$ & Mean $\pm \mathrm{SD}$ \\
\hline Left ventricular ejection fraction $(\%)$ & 187 & $72.0 \pm 0.2$ & & 228 & $72.0 \pm 0.3$ \\
Left ventricle mass index $\left(\mathrm{g} / \mathrm{m}^{2}\right)$ & 179 & $78.2 \pm 1$ & & 220 & $70.1 \pm 0.8^{*}$ \\
\hline
\end{tabular}

${ }^{*} \mathrm{P}<0.05$ compared to men (Student $t$-test). men. Other baseline clinical characteristics studied did not reveal statistically significant differences between men and women (Tables 2 and 3).

\section{Treadmill electrocardiographic exercise stress test}

a) Heart rate: 222 (92.1\%) women and 186 (93\%) men reached $85 \%$ of age-predicted peak exercise heart rate. Heart rate recovery in the 1 st and 2 nd min after exercise was faster in women (Table 4). A non-significant trend for a decrease in the heart rate recovery with increasing age for men and women was apparent (Figure 1).

Nine $(3.7 \%)$ women and $13(6.5 \%)$ men demonstrated heart rate recovery in the $1 \mathrm{st}$ min of recovery $<12 \mathrm{bpm}$. An age increase of one year was associated with a $6 \%$ increase in risk of heart rate recovery $<12 \mathrm{bpm}$ in the $1 \mathrm{st}$ min of recovery $(P=0.005$; risk ratio $=1.06$; $95 \%$ confidence interval $(\mathrm{Cl})=1.02-1.1)$. At the 2 nd min of recovery, two $(1 \%)$ women and four $(2 \%)$ men demonstrated heart rate recovery $<22 \mathrm{bpm}$. There was no influence of age or gender on the 2 nd min of heart rate recovery.

b) ST-segment: Upslope morphology of the ST-segment and magnitude $<0.1 \mathrm{mV}$ were observed in 225 (93.3\%) women and in 191 (95.5\%) men. Sixteen (6.7\%) women and $9(4.5 \%)$ men demonstrated ST-segment upslope $\geq 0.15$ $\mathrm{mV}$ or downslope $\geq 0.1 \mathrm{mV}$. This finding was more frequent in lead II $(5.44 \%)$, followed by lead $V_{5}(2.73 \%)$ and lead $V_{2}$ (0.23\%; II vs $\mathrm{V}_{2}, \mathrm{P}<0.0001$; II vs $\mathrm{V}_{5}, \mathrm{P}=0.001 ; \mathrm{V}_{2}$ vs $\mathrm{V}_{5}$, $P=0.02)$. An age increase of 1 year increased by $4 \%(P=$ 0.03 ; risk ratio $=1.040,95 \% \mathrm{Cl}=1.002-1.080$ ) the chance of upsloping of segment ST $\geq 0.15 \mathrm{mV}$ or downsloping of segment ST $\geq 0.1 \mathrm{mV}$. The difference was not significant relative to sex.

c) $R$ and $Q$ wave amplitude: There was a trend to a

Table 4. Treadmill electrocardiographic exercise stress test characteristics of the men and women of the study sample.

\begin{tabular}{|c|c|c|c|c|}
\hline \multirow[t]{2}{*}{ Variables } & \multicolumn{2}{|r|}{ Men } & \multicolumn{2}{|r|}{ Women } \\
\hline & $\mathrm{N}$ & Mean \pm SD & $\mathrm{N}$ & Mean \pm SD \\
\hline Baseline heart rate (bpm) & 200 & $77.9 \pm 0.9$ & 241 & $82.9 \pm 0.8^{*}$ \\
\hline Peak exercise heart rate (bpm) & 200 & $171.5 \pm 1$ & 241 & $170.1 \pm 0.9$ \\
\hline Heart rate recovery 1st min (bpm) & 155 & $143.5 \pm 1.1$ & 207 & $139.2 \pm 1.3^{*}$ \\
\hline Heart rate recovery 2nd min (bpm) & 180 & $123.2 \pm 1.1$ & 216 & $117.2 \pm 1.2^{*}$ \\
\hline Baseline systolic blood pressure (mmHg) & 200 & $124.5 \pm 0.7$ & 241 & $119.5 \pm 0.7^{*}$ \\
\hline Peak exercise systolic blood pressure $(\mathrm{mmHg})$ & 200 & $181.0 \pm 1.6$ & 241 & $166.8 \pm 1.7^{*}$ \\
\hline Baseline diastolic blood pressure $(\mathrm{mmHg})$ & 200 & $78.7 \pm 0.6$ & 241 & $77.1 \pm 0.6$ \\
\hline Peak exercise diastolic blood pressure $(\mathrm{mmHg})$ & 200 & $84.2 \pm 0.9$ & 241 & $81.5 \pm 0.8^{*}$ \\
\hline Rate-pressure product (bpm $\times$ mmHg) & 200 & $31023.6 \pm 321.7$ & 241 & $28378.7 \pm 313.1^{*}$ \\
\hline Exercise duration (min) & 200 & $8.4 \pm 0.1$ & 241 & $6.9 \pm 0.1^{*}$ \\
\hline Exercise capacity (MET) & 188 & $12.7 \pm 0.2$ & 228 & $10.4 \pm 0.2^{*}$ \\
\hline
\end{tabular}

MET = metabolic equivalent. ${ }^{*} \mathrm{P}<0.05$ compared to men (Student $t$-test). 
decrease in $\mathrm{R}$ wave amplitude and to an increase in $\mathrm{Q}$ wave at peak exercise relative to baseline values for both genders.

The decrease in $\mathrm{R}$ wave amplitude at peak of exercise in leads $V_{2}$ and $V_{5}$, the sum of $R$ wave's amplitude in leads

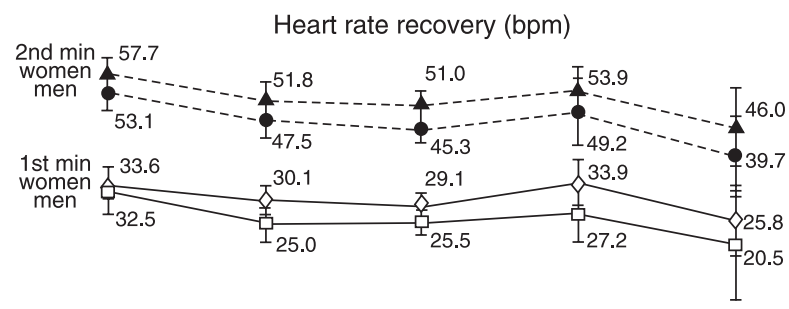

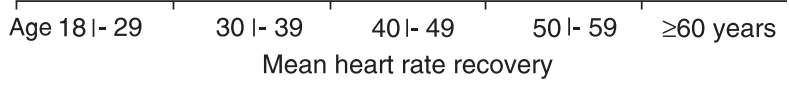

1st min: men $26.6 \pm 0.8$ vs women $30.9 \pm 0.7 ; P=0.002$ 2nd min: men $47.9 \pm 0.8$ vs women $52.9 \pm 0.8 ; \mathrm{P}<0.001$

Figure 1. Mean heart rate recovery in the $1 \mathrm{st}$ and $2 \mathrm{nd}$ min after exercise relative to age and gender. (Student $t$-test).

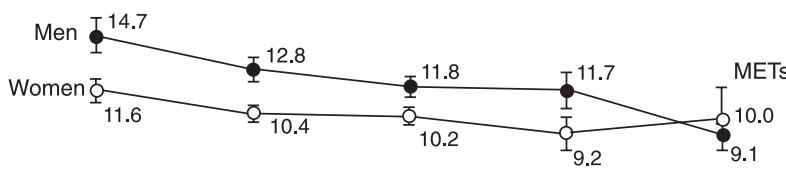

\begin{tabular}{|c|c|c|c|c|}
\hline Age $18 \mid-29$ & $30 \mid-39$ & $40 \mid-49$ & $50 \mid-59$ & $\geq 60$ years \\
\hline
\end{tabular}

Figure 2. Mean of estimated exercise capacity in metabolic equivalents (METs) during treadmill exercise stress testing relative to age and gender. (Student $t$-test).

Table 5. Differences between baseline and peak exercise in blood pressure, $\mathrm{R}$ wave amplitude and $\mathrm{Q}$ wave amplitude in men and women.

\begin{tabular}{lcc}
\hline Variables & Men $(\mathrm{N}=200)$ & Women $(\mathrm{N}=241)$ \\
\hline Systolic blood pressure $(\mathrm{mmHg})$ & $56.5 \pm 1.6$ & $47.3 \pm 1.6^{*}$ \\
Diastolic blood pressure $(\mathrm{mmHg})$ & $5.5 \pm 0.8$ & $4.4 \pm 0.7$ \\
$\mathrm{R}$ wave in II $(\mathrm{mm})$ & $-2.7 \pm 0.2$ & $-2.2 \pm 0.2$ \\
$\mathrm{R}$ wave in $\mathrm{V}_{2}(\mathrm{~mm})$ & $-1.4 \pm 0.1$ & $-0.8 \pm 0.1^{*}$ \\
$\mathrm{R}$ wave in $\mathrm{V}_{5}(\mathrm{~mm})$ & $-2.1 \pm 0.1$ & $-1.3 \pm 0.2^{*}$ \\
$\mathrm{R}$ wave $\left(\mathrm{II}+\mathrm{V}_{2}+\mathrm{V}_{5}\right)(\mathrm{mm})$ & $-6.2 \pm 0.4$ & $-4.3 \pm 0.3^{*}$ \\
Q wave in $\mathrm{V}_{5}(\mathrm{~mm})$ & $0.5 \pm 0.0$ & $0.4 \pm 0.0$
\end{tabular}

Data are reported as means $\pm \mathrm{SD}$. ${ }^{*} \mathrm{P}<0.05$ compared to men (Student $t$-test).
II, $\mathrm{V}_{2}$ and $\mathrm{V}_{5}$ were higher in men (Table 5).

The normal decrease in $\mathrm{R}$ wave amplitude at peak exercise was more apparent with the sum of leads II, $V_{2}$ and $\mathrm{V}_{5}$ (observed in 342 participants) than $\mathrm{R}$ wave amplitude measured in the $V_{5}$ lead (observed in 283 participants).

Among 8 patients with ST-segment downsloping in lead $V_{5}$, three patients demonstrated a diminished $Q$ wave in lead $\mathrm{V}_{5}$ at peak exercise.

d) Blood pressure: Baseline mean systolic blood pressure, peak exercise systolic and diastolic blood pressure and differences between peak exercise and baseline systolic blood pressure were higher in men (Tables 4 and 5).

An increase of systolic blood pressure $\leq 30 \mathrm{mmHg}$ was observed in $56(23.2 \%)$ women and 28 (14\%) men. The chance of women to show an increase of systolic blood pressure $\leq 30 \mathrm{mmHg}$ was $85 \%$ higher than men $(\mathrm{P}=0.01$; risk ratio $=1.85,95 \% \mathrm{Cl}=1.1-3.05)$.

e) Rate-pressure product: The rate-pressure product was higher in men (Table 4). A rate-pressure product $<30.0 \mathrm{bpm} \cdot \mathrm{mmHg}^{-1} \cdot\left(10^{-3}\right)^{-1}$ was observed in $159(65.9 \%)$ women and in $81(40.5 \%)$ men. The chance of a ratepressure product $<30.0 \mathrm{bpm} \cdot \mathrm{mmHg}^{-1} \cdot\left(10^{-3}\right)^{-1}$ for women was almost three times higher than for men $(P=0.001$; risk ratio $=2.96,95 \% \mathrm{Cl}=2.0-4.39$ ). For an age increase of 1 year, the chance of a rate-pressure product $<30.0$ $\mathrm{bpm} \cdot \mathrm{mmHg}^{-1} \cdot\left(10^{-3}\right)^{-1}$ increased $3 \%(\mathrm{P}=0.002$; risk ratio $=1.03,95 \% \mathrm{Cl}=1.01-1.05)$.

f) Estimated exercise capacity: Exercise duration and estimated exercise capacity were higher in men (Table 4). A trend to a decrease in estimated exercise capacity with increasing age was verified for men and women up to 59 years of age (Figure 2).

\section{Discussion}

We observed statistically significant differences between healthy men and women after the beginning of the electrocardiographic exercise stress test for peak exercise systolic blood pressure and diastolic blood pressure, ratepressure product, $\mathrm{R}$ wave amplitude, exercise duration, and estimated exercise capacity. During recovery after exercise, differences were significant for heart rate recovery in the 1st and 2nd min after exercise. In contrast, we did not observe significant differences in the treadmill electrocardiographic exercise stress test between men and women for ST-segment, for peak exercise heart rate or $Q$ wave amplitude.

Heart rate recovery was faster in women and this difference persisted, though not statistically significant, from the $3 \mathrm{rd}$ to the 7 th decade of age. This finding raises the question of whether the mechanism of parasympathetic reactivation after exercise may be more pronounced in women. In a previous study, there was no significant correlation between heart rate recovery and autonomic function evaluated by heart rate variability during the 1 st and 2 nd min after exercise. 
The SDNN, SDANN, SDNNi, rMSSD, and pNN50 indices were correlated significantly with heart rate recovery only at the 3rd and 4th min of recovery (16).

Fewer women $(3.7 \%)$ than men $(6.5 \%)$ showed a heart rate recovery after exercise below $12 \mathrm{bpm}$ and the probability of this finding increased with age. This was an interesting finding in the absence of any evidence of heart disease since previous studies have rated $12 \mathrm{bpm}$ as a marker of less favorable prognosis $(6,17)$.

We observed an ST-segment upslope $\geq 0.15 \mathrm{mV}$ or downslope $\geq 0.1 \mathrm{mV}$ in $16(6.7 \%)$ women and $9(4.5 \%)$ men, lower than the range of 14 to $67 \%$ of previously reported cases (12). This lower frequency may have been related to the criteria used for enrollment in the present study, namely asymptomatic subjects with normal clinic examination, baseline electrocardiogram, chest X-ray, and echocardiogram.

In the present series, ST-segment upslope $\geq 0.15 \mathrm{mV}$ or downslope $\geq 0.1 \mathrm{mV}$ was observed more frequently in lead II. In patients with a normal resting electrocardiogram, exercise-induced ST-segment depression confined to the inferior leads is of little value for the identification of coronary disease $(12,18)$.

We did not observe significant differences between men and women in ST-segment during the treadmill electrocardiographic exercise stress test. This observation contrasts with the long held view in clinical practice that ST abnormalities may be more frequent in women than in men $(4,12)$.

The normal decrease in $\mathrm{R}$ wave amplitude at peak exercise was more apparent with the sum of leads II, $V_{2}$ and $V_{5}$ (observed in $342 / 441$ participants, $76 \%$ ) than the $R$ wave amplitude measure in $V_{5}$ lead (observed in 283/441 participants, $64 \%$ ). This finding suggests that $\mathrm{R}$ wave amplitude may be better analyzed in leads II, $V_{2}$ and $V_{5}$, and not in a single lead. Other investigators have shown that $\mathrm{R}$ wave amplitude in the lateral precordial leads usually decreases more in healthy subjects than in patients and a significant correlation with left ventricular function has been demonstrated (12,19-22).

Most patients demonstrated an increase in $Q$ wave amplitude at peak exercise, as shown in previous studies $(23,24)$. However, among 8 patients with ST-segment downsloping in lead $V_{5}$, three demonstrated a diminished $Q$ wave in lead $V_{5}$ at peak exercise. This finding was unexpected in this setting; whether it means an abnormal result

\section{References}

1. Manca C, Dei Cas L, Albertini D, Baldi G, Visioli O. Different prognostic value of exercise electrocardiogram in men and women. Cardiology 1978; 63: 312-319.

2. Alexander KP, Shaw LJ, Shaw LK, DeLong ER, Mark DB, Peterson ED. Value of exercise treadmill testing in women. remains to be established.

Baseline mean systolic blood pressure and peak exercise systolic and diastolic blood pressure were higher in men, as also observed by others $(13,25,26)$. This finding in women may be attributed to their smaller muscle mass, lower hemoglobin and blood volume, and smaller stroke volume compared with men.

It is noteworthy that an increase of systolic blood pressure $\leq 30 \mathrm{mmHg}$ was observed in $23.2 \%$ of women and $14 \%$ of men. The chance of women showing an increase of systolic blood pressure $\leq 30 \mathrm{mmHg}$ is $85 \%$ higher than in men. Thus, this finding may be detected in otherwise healthy individuals, and may be ascribed to poor physical conditioning.

We observed influence of gender and age on the ratepressure product. The chance of a rate-pressure product $<30 \mathrm{bpm} \cdot \mathrm{mmHg}^{-1} \cdot\left(10^{-3}\right)^{-1}$ for women was almost three times higher than for men and, for an age increase of one year, the chance of a rate-pressure product $<30 \mathrm{bpm} . \mathrm{mmHg}^{-1}$. $\left(10^{-3}\right)^{-1}$ increased by $3 \%$. This was an expected finding since the rate-pressure product depends on both systolic blood pressure and heart rate.

Functional capacity was higher in men than in women and tended to decrease with age for both genders, as also observed by others $(27,28)$. Maximal aerobic capacity declines 8 to $10 \%$ per decade in sedentary men and women (27). In the present study, this decline was observed in the second, third, fourth, and sixth decade for men and in the third and fifth decade for women, a trend similar to that observed in other studies $(27,28)$.

The present study has limitations. The sample was recruited from asymptomatic volunteers with normal clinical and laboratory examination and may not be representative of the whole population. Few individuals were older than 60 years of age and elderly subjects were under-represented. Additionally, further invasive diagnostic work-up was not recommended to the participants.

We were not able to demonstrate differences in the frequency of ST-segment changes in men and women submitted to an electrocardiographic exercise stress test. Our findings for this study sample do not support the previously suggested contention of different frequencies of ST-T wave changes in men and women. Other differences observed between men and women were more subtle and may have been related to different physical conditioning.

J Am Coll Cardiol 1998; 32: 1657-1664.

3. Lauer MS, Pothier CE, Magid DJ, Smith SS, Kattan MW. An externally validated model for predicting long-term survival after exercise treadmill testing in patients with suspected coronary artery disease and a normal electrocardiogram. 
Ann Intern Med 2007; 147: 821-828.

4. Gibbons RJ, Balady GJ, Beasley JW, Bricker JT, Duvernoy WF, Froelicher VF, et al. ACC/AHA Guidelines for Exercise Testing. A report of the American College of Cardiology/ American Heart Association Task Force on Practice Guidelines (Committee on Exercise Testing). J Am Coll Cardiol 1997; 30: 260-311.

5. Hlatky MA, Pryor DB, Harrell FE Jr, Califf RM, Mark DB, Rosati RA. Factors affecting sensitivity and specificity of exercise electrocardiography. Multivariable analysis. Am J Med 1984; 77: 64-71.

6. Cole CR, Blackstone EH, Pashkow FJ, Snader CE, Lauer MS. Heart-rate recovery immediately after exercise as a predictor of mortality. N Engl J Med 1999; 341: 1351-1357.

7. Cole CR, Foody JM, Blackstone EH, Lauer MS. Heart rate recovery after submaximal exercise testing as a predictor of mortality in a cardiovascularly healthy cohort. Ann Intern Med 2000; 132: 552-555.

8. Shetler K, Marcus R, Froelicher VF, Vora S, Kalisetti D, Prakash $\mathrm{M}$, et al. Heart rate recovery: validation and methodologic issues. J Am Coll Cardiol 2001; 38: 1980-1987.

9. Singh JP, Larson MG, Manolio TA, O'Donnell CJ, Lauer M, Evans JC, et al. Blood pressure response during treadmill testing as a risk factor for new-onset hypertension. The Framingham heart study. Circulation 1999; 99: 1831-1836.

10. Kurl S, Laukkanen JA, Rauramaa R, Lakka TA, Sivenius J, Salonen JT. Systolic blood pressure response to exercise stress test and risk of stroke. Stroke 2001; 32: 2036-2041.

11. Lang RM, Bierig M, Devereux RB, Flachskampf FA, Foster E, Pellikka PA, et al. Recommendations for chamber quantification: a report from the American Society of Echocardiography's Guidelines and Standards Committee and the Chamber Quantification Writing Group, developed in conjunction with the European Association of Echocardiography, a branch of the European Society of Cardiology. J Am Soc Echocardiogr 2005; 18: 1440-1463.

12. Ellestad MH, Davis FA. Stress testing: Principles and practice. 5th edn. New York: Oxford University Press; 2003.

13. Andrade J, Brito FS, Vilas-Boas F, Castro I, Oliveira JÁ, Guimarães JI, et al. Exercise testing guidelines of Brazilian Society of Cardiology. Arq Bras Cardiol 2002; 78 (Suppl I): 1-18.

14. Stokes ME. Categorical data analysis using the SAS system. 1st edn. Cary: SAS Institute, Inc.; 1995.

15. Agrest A. Categorical data analysis. 2nd edn. New Jersey: John Wiley \& Sons; 2002.

16. Antelmi I, Chuang EY, Grupi CJ, Latorre MR, Mansur AJ. Heart rate recovery after treadmill electrocardiographic ex- ercise stress test and 24-hour heart rate variability in healthy individuals. Arq Bras Cardiol 2008; 90: 380-385.

17. Nishime EO, Cole CR, Blackstone EH, Pashkow FJ, Lauer MS. Heart rate recovery and treadmill exercise score as predictors of mortality in patients referred for exercise ECG. JAMA 2000; 284: 1392-1398.

18. Miranda CP, Liu J, Kadar A, Janosi A, Froning J, Lehmann $K G$, et al. Usefulness of exercise-induced ST-segment depression in the inferior leads during exercise testing as a marker for coronary artery disease. Am J Cardiol 1992; 69: 303-307.

19. Bonoris PE, Greenberg PS, Christison GW, Castellanet $\mathrm{MJ}$, Ellestad $\mathrm{MH}$. Evaluation of $\mathrm{R}$ wave amplitude changes versus ST-segment depression in stress testing. Circulation 1978; 57: 904-910.

20. Degre S, Longo B, Thirion M, Stoupel E, Sobolski J, Berkenboom G, et al. Analysis of exercise-induced R-waveamplitude changes in detection of coronary artery disease in patients with typical or atypical chest pain under digitalis treatment. Cardiology 1981; 68 (Suppl 2): 178-185.

21. Greenberg PS, Ellestad MH, Berge R, Johnson K, Hayes M, Bible $\mathrm{M}$, et al. Radionuclide angiographic correlation of the $\mathrm{R}$ wave, ejection fraction, and volume responses to upright bicycle exercise. Chest 1981; 80: 459-464.

22. Fox K, Selwyn A, Shillingford J. Precordial electrocardiographic mapping after exercise in the diagnosis of coronary artery disease. Am J Cardiol 1979; 43: 541-546.

23. Morales-Ballejo H, Greenberg PS, Ellestad MH, Bible M. Septal $Q$ wave in exercise testing: angiographic correlation. Am J Cardiol 1981; 48: 247-251.

24. O'Hara MJ, Subramanian VB, Davies AB, Raftery EB. Changes of $Q$ wave amplitude during exercise for the prediction of coronary artery disease. Int J Cardiol 1984; 6: 35-45.

25. Michelsen S, Otterstad JE. Blood pressure response during maximal exercise in apparently healthy men and women. $J$ Intern Med 1990; 227: 157-163.

26. Daida H, Allison TG, Squires RW, Miller TD, Gau GT. Peak exercise blood pressure stratified by age and gender in apparently healthy subjects. Mayo Clin Proc 1996; 71: 445452.

27. Fletcher GF, Balady GJ, Amsterdam EA, Chaitman B, Eckel $\mathrm{R}$, Fleg J, et al. Exercise standards for testing and training: a statement for healthcare professionals from the American Heart Association. Circulation 2001; 104: 1694-1740.

28. Kligfield P, Lauer MS. Exercise electrocardiogram testing: beyond the ST segment. Circulation 2006; 114: 20702082. 